\title{
REVISÃO ANALÍTICA DOS \\ DESAFIOS DA EDUCAÇÃO AMBIENTAL NO ÂMBITO ESCOLAR EM DOCUMENTOS OFICIAIS E ARTIGOS RELACIONADOS
}

\author{
Maria Betânia da Silva Carvalho' \\ Vilma Bragas de Oliveira ${ }^{2}$
}

Resumo: $O$ presente artigo aborda os desafios para a práxis pedagógica da Educação Ambiental, e destaca a discussão em volta da EA não ser uma disciplina específica, dada a sua importância como agente transformador, pois ela compõe o grupo dos temas transversais conforme os PCNs. Com isso, é necessário superar os desafios que a prática da EA apresenta, buscando por caminhos teórico-metodológicos que promovam uma prática que envolva todo o caráter da EA por meio de metodologias que desencadeiam uma postura interdisciplinar, crítica, reflexiva, participativa, transversal e emancipatória como afirma: REIGOTA (1994), SATO (2002), SAUVÉ (2005), e DIMAS (2021) e em documento oficiais como a BNCC, os PCN, as DCN e a PNEA.

Palavras-chave: Educação Ambiental; Ensino; Transversal.

Abstract: This article addresses the challenges for the pedagogical praxis of Environmental Education, and highlights the discussion around EE not being a specific discipline, given its importance as a transformative agent, as it composes the group of transversal themes according to the PCNs. Thus, it is necessary to overcome the challenges that the practice of EE presents, seeking theoretical-methodological ways that promote a practice that involves the entire character of EE through methodologies that trigger an interdisciplinary, critical, reflective, participatory, transversal and emancipatory as stated by: REIGOTA (1994), SATO (2002), SAUVÉ (2005), and DIMAS (2021) and in official documents such as the BNCC, the PCN, the DCN and the PNEA.

Keywords: Environmental Education; Teaching; Cross-Sectional.

1 Universidade Federal do Maranhão. E-mail: betania.maria@discente.ufma.br

2 Universidade Estadual do Norte Fluminense Darcy Ribeiro - UENF. E-mail: vilma.bragas@ufma.br

Revbea, São Paulo, V. 16, № 6: 448-465, 2021. 


\section{Introdução}

A Educação Ambiental (EA) constitui uma dimensão fundamental e de grande potencial para auxiliar na construção de uma visão sustentável nos indivíduos, e consequentemente, em todas as esferas sociais. Segundo OLIVEIRA (2010) a EA possui um papel essencial para que o processo de transformação atitudinal e não somente discursivo ocorra de fato na sociedade.

A EA possui importantes marcos históricos e legislativos no decorrer dos últimos 50 anos, aproximadamente em 1977 ocorreu a Conferência Intergovernamental de Educação Ambiental de Tbilisi, na Geórgia, promovida pela UNESCO e pelo programa de meio ambiente da ONU (PNUMA), onde suas definições ainda são utilizadas mundialmente.

Em 1992 outro documento de extrema importância para a EA foi o Tratado de Educação Ambiental para Sociedades Sustentáveis e Responsabilidade Global, durante a Conferência da ONU sobre Meio Ambiente e Desenvolvimento (Rio-92). Em âmbito nacional a Educação Ambiental, do mesmo modo, teve grandes conquistas como o assegurado pela Constituição Federal de 1988, a Lei de Diretrizes e Bases (LDB) de 1996 e a Política Nacional de Educação Ambiental (PNEA) Lei $n^{\circ}$ 9.775/99, regulamentada pelo Decreto $n^{\circ} 4.281 / 02$.

Diante do cenário atual, em que as problemáticas ambientais são tangíveis e gritantes, as discussões em torno deste tema têm sofrido um expressivo aumento, em virtude disso, temos as criações de Leis que regulamentam e orientam, em reflexo da intensificação das discussões da presente temática. Como citado anteriormente, no ano de 1999 foi criada a Política Nacional de Educação Ambiental (PNEA) que em seu artigo $1^{\circ}$ afirma: Entendem-se por Educação Ambiental os processos por meio dos quais 0 indivíduo e a coletividade constroem valores sociais, conhecimentos, habilidades, atitudes e competências voltadas para a conservação do meio ambiente, bem de uso comum do povo, essencial à sadia qualidade de vida e sustentabilidade.

Ante o exposto, a EA constitui a somatória do processo de construção de um comportamento que vai além do individual, enfatizando a responsabilidade de todos, com o fim de alcançar uma sociedade consciente, com o sentimento de respeito ao meio ambiente e de compromisso em preservar e cuidar dos recursos naturais.

Para atingir este fim, o conhecimento é o principal instrumento para desenvolver uma visão mais clara e sensível, em relação ao estado preocupante em que se encontra os impactos ambientais, perceptíveis não somente de maneira centralizada, todavia de forma mundial e acelerada, onde todas as espécies do ecossistema do planeta são atingidas, estando elas na água, solo e até mesmo no ar. Isto posto, é primordial que o conhecimento acerca dessa realidade seja propagado e enfatizado. 
Neste sentido, cabe questionar, como tem sido construído e vivenciado o Projeto Político Pedagógico nas escolas, sejam elas públicas, privadas, de meio urbano ou rural; pois todas devem construir suas intenções a partir de fundamentos, concepções e metodologias que levem os educandos, a refletirem sobre as questões ambientais, construído conhecimento e competências fundamentais para transformar a realidade que os cerca (SILVA; GRZEBIELUKA, 2015)

Moura e Hirata (2013) enfatizam que a EA tem por finalidade a implementação de uma sociedade mais crítica e com modo de leitura de mundo mais complacente e pertencente, tendo em vista que a prática da Educação Ambiental possui numerosos desafios e dificuldades na educação formal, mas que necessitam ser superadas para que haja uma prática educativa eficaz para alcançar os resultados propostos pela EA.

Um dos desafios para a sua práxis pedagógica é a discussão em volta da EA não ser uma disciplina específica, dada a sua importância como agente transformador, pois ela compõe o grupo dos temas transversais conforme os Parâmetros Curriculares Nacionais (PCNs).

Outrossim, é a Base Nacional Comum Curricular não conter o termo Educação Ambiental na escrita, mas apenas assegura a promoção de um pensamento socioambiental no seu texto, o que promove uma desvalorização desta temática na educação básica (BARBOSA; OLIVEIRA, 2020, p. 4).

É válido ressaltar, além do supracitado, que a prática da EA de forma efetiva enfrenta outro grande desafio, no que concerne as metodologias utilizadas pelos educadores, na qual, evidencia um sentimento do homem estar alheio às problemáticas ambientais, o que fomenta uma ineficiência nos resultados atingidos, considerando os propósitos da Educação Ambiental, como pontua Machado e Terán (2018):

A EA não é trabalhada da forma correta em boa parte das instituições de ensino, que optam por tratar o tema sob uma perspectiva de senso comum e superficialismo, afinal, a contemplação do meio ambiente, de maneira isolada e sem contextualização, dificilmente produzirá uma aprendizagem significativa.

Isto posto, é mister que a Educação Ambiental seja olhada por meio da relevância da dimensão deste tema, tendo em vista, que ela trata de problemas que exigem premência em mudanças comportamentais de toda a sociedade. As escolas por sua vez, são geradoras de transformações, através do conhecimento, o que as torna aliadas indispensáveis, na difusão da 
mentalidade pautada na interação e na conservação com o meio e todos os recursos energéticos.

O referente trabalho objetiva analisar os desafios da Educação Ambiental no âmbito escolar, partindo do ano de 1994 até o ano de 2021, utilizando como metodologia uma revisão literária de autores como: REIGOTA (1994), SATO (2002), SAUVÉ (2005), e DIMAS (2021) e em documentos oficiais como a Base Nacional Comum Curricular (BNCC), os Parâmetros Curriculares Nacionais (PCNs), as Diretrizes Curriculares Nacionais (DCNs) e a Política Nacional de Educação Ambiental (PNEA). Há uma extrema necessidade de abordar a Educação Ambiental nas escolas, e principalmente que seja praticada de maneira eficaz, tendo em vista a necessidade de transformação nos sujeitos diante da realidade socioambiental.

\section{Generalidade sobre Educação Ambiental}

A Educação Ambiental enfrenta diversos desafios para ser implantada e desenvolvida no ambiente escolar, como a busca por alternativas metodológicas eficazes, o entendimento da magnitude da dimensão ambiental, e o enfrentamento da visão alheia do ser humano, com relação ao meio ambiente. Contudo é necessário destacar, que mesmo com os desafios existentes é preciso buscar por soluções e construir uma EA que fomente 0 respeito a todo o ecossistema.

Os Parâmetros Curriculares Nacionais (PCNs) por sua vez, asseguram que é necessário a construção de uma consciência sustentável, colaborativa e que a abordagem da EA seja posta de forma interdisciplinar, onde os sujeitos desenvolvam uma conduta enraizada no respeito ao meio ambiente e se torne participativo e atuante diante das problemáticas ambientais locais e globais.

A Educação Ambiental nas escolas passa por inúmeras barreiras, que vão desde a busca por alternativas metodológicas, falta da elaboração de Projetos Políticos Pedagógicos (PPPs) que contenha a EA, até a falta de formações continuadas aos docentes para trabalharem a temática, considerando-se as dificuldades apresentadas na prática da EA (OLIVEIRA, 2000).

Os desafios no desenvolvimento da EA acarretaram implicações na implantação da dimensão da Educação Ambiental no âmbito escolar, prejudicando os resultados que se almeja alcançar na mentalidade de todos os inseridos na comunidade. Dado que, despertar a consciência dos problemas ambientais na sociedade é algo imprescindível, no entanto, saber tratar desta temática é tão ou mais importante do que tão somente conhecê-la (BOSA; TESSER, 2014, p. 1).

A escola possui um papel indispensável na propagação de uma mudança socioambiental, uma vez que por meio dela é possível atingir e 
influenciar na criação de um pensamento crítico referente às questões ambientais, como afirma BOSA e TESSER (2014):

A interatividade da Educação Ambiental com a sociedade ocorre principalmente no âmbito escolar, por isso, é na escola que podemos encontrar a principal fonte dispersora da consciência ambiental. Contudo, na maioria das vezes as fragilidades do ensino tanto em seu espaço físico quanto na falta de preparo dos professores impedem que a Educação Ambiental seja aplicada de maneira satisfatória.

Diante disso, é de extrema relevância que as instituições de ensino tenham a consciência que é necessário superar os desafios e obstáculos que a prática da EA apresenta, assim como o corpo docente e discente e os demais componentes da comunidade, como aponta Narcizo (apud NETO et al., 2009):

Entretanto, a Educação Ambiental deve ser vista de forma prazerosa, e não somente porque a legislação trata. Ainda que difícil de ser desenvolvida, pois requer atitudes concretas, como mudanças de comportamento pessoal e comunitário, tendo em vista que as dificuldades são grandes quando se quer trabalhar verdadeiramente a Educação Ambiental, mas precisam ser enfrentadas.

Reigota (apud NETO et al., 2004) destaca que a EA está em constante interação com as vertentes sociais, políticas e culturais. Por isso a EA está além de apenas uma simples abordagem interdisciplinar nas aulas do período letivo, ela corresponde a um conjunto de estratégia que requer antes de tudo, uma compreensão da sua magnitude para ser abordada no cotidiano escolar, e promova uma mudança de pensamento.

Sauvé (2005) por sua vez ressalta que o educador deve levar em consideração as múltiplas facetas da relação homem-natureza, para que o alunado tenha uma melhor assimilação durante a abordagem do tema. Em contrapartida, o educador de antemão deve conhecer e entender o que de fato é a Educação Ambiental. Ainda conforme Sauvé (2005):

A Educação Ambiental não é, portanto, uma forma de educação (uma educação para...) entre inúmeras outras; não é simplesmente uma ferramenta para a resolução de problemas ou de gestão do meio ambiente. Trata-se de uma dimensão essencial da educação fundamental que diz respeito a uma esfera de interações que está na base do desenvolvimento pessoal e social: a da relação com o meio em que vivemos, 
com essa casa de vida compartilhada. A Educação Ambiental visa a induzir dinâmicas sociais, de início na comunidade local e, posteriormente, em redes mais amplas de solidariedade, promovendo a abordagem colaborativa e crítica das realidades socioambientais e uma compreensão autônoma e criativa dos problemas que se apresentam e das soluções possíveis para eles.

Exposto isto, evidencia-se a necessidade do domínio sobre o entendimento da dimensão que condiz a Educação Ambiental, e na ausência dele ocorre limitações e óbice na práxis, culminando em defasagem na resulta do processo de exercício da Educação Ambiental na sala de aula. Além de buscar metodologias pertinentes e significativas no contexto ambiental e local dos alunos (DIMAS et al, 2021, p.3).

Haja vista que além do citado, há um sentimento enraizado no ser humano, de estar a parte do ecossistema, proveniente de uma cultura onde se acreditava que a natureza possuía recursos infinitos. Logo esse sentimento inviabiliza a efetivação do diálogo e crescimento do pensamento sustentável de valorização do ambiente ao redor (ROVANI, 2010, p.1). É necessário trabalhar esta temática de uma maneira abrangente e com um olhar de totalidade nos aspectos que tecem a EA.

\begin{abstract}
Assim, ao discutir sobre a temática ambiental na escola é necessário abordá-la a partir de uma perspectiva ampla e multifacetada. Não se trata apenas de ensinar os alunos a reciclarem, limitação frequente nas escolas de hoje em dia, o trabalho deve ir muito além. É preciso que os educadores elucidem as inter-relações entre indivíduos e ecossistemas, entre responsabilidade na manutenção da equidade e na percepção das nuances envolvendo todas essas dimensões. Logo, o trabalho com o meio ambiente na escola deve orientar os alunos na construção de sua autonomia e proatividade frente aos desafios da sociedade local e global, além de mostrar os instrumentos e procedimentos com os quais os alunos devem trabalhar para materializar seus desejos de ter uma sociedade melhor (MACHADO; TERÁN, 2018):
\end{abstract}

Em corroboração a esta afirmação dos objetivos da EA no contexto escolar, a Lei 9.795 , de 27 de abril de 1999 , no artigo $4^{\circ}$, aponta para a dimensão que constitui a EA, com isso clareia a concepção sobre a grandiosidade e amplitude dos princípios e objetivos da Educação Ambiental com relação às concepções ambientais em todas as suas vertentes, com uma perspectiva pautada na transversalidade, ou seja, devendo ser trabalhada de maneira interdisciplinar. 
Art. $4^{\circ}$ São princípios básicos da Educação Ambiental:

I o enfoque humanista, holístico, democrático e participativo;

II a concepção do meio ambiente em sua totalidade, considerando a interdependência entre 0 meio natural, o socioeconômico e 0 cultural, sob 0 enfoque da sustentabilidade;

III o pluralismo de ideias e concepções pedagógicas, na perspectiva da inter, multi e transdisciplinaridade;

IV a vinculação entre a ética, a educação, o trabalho e as práticas sociais;

$\mathrm{V}$ a garantia de continuidade e permanência do processo educativo;

VI a permanente avaliação crítica do processo educativo;

VII a abordagem articulada das questões ambientais locais, regionais, nacionais e globais;

VIII o reconhecimento e o respeito à pluralidade e à diversidade individual e cultural.

Somando a isso, no artigo $5^{\circ}$ da presente Lei supracitada reforça esta declaração ao estabelecer a produção de um entendimento completo, que tenha como pilar a compreensão dos aspectos políticos, sociais e científicos, com isso visa estimular e instigar o fortalecimento da criação de uma postura crítica, reflexiva e ativa dos sujeitos diante da situação catastrófica do contexto ecológico do planeta, além de promover o incentivo a atuação individual e comunitária na conservação do equilíbrio ambiental e dar enfoque à indissolução do exercício da cidadania com a defesa da qualidade do meio ambiente, corrobora além do citado, o incitamento à cooperação entre as regiões do país, tendo por objetivo a fundamentação de uma sociedade enraizada em princípios democráticos, responsáveis, sustentáveis e solidários.

Art. $5^{\circ}$ São objetivos fundamentais da Educação Ambiental:

I o desenvolvimento de uma compreensão integrada do meio ambiente em suas múltiplas e complexas relações, envolvendo aspectos ecológicos, psicológicos, legais, políticos, sociais, econômicos, científicos, culturais e éticos;

II a garantia de democratização das informações ambientais;

III o estímulo e o fortalecimento de uma consciência crítica sobre a problemática ambiental e social;

IV o incentivo à participação individual e coletiva, permanente e responsável, na preservação do equilíbrio do meio ambiente, entendendo-se a defesa da qualidade ambiental como um valor inseparável do exercício da cidadania; 
V o estímulo à cooperação entre as diversas regiões do País, em níveis micro e macrorregionais, com vistas à construção de uma sociedade ambientalmente equilibrada, fundada nos princípios da liberdade, igualdade, solidariedade, democracia, justiça social, responsabilidade e sustentabilidade;

VI o fomento e o fortalecimento da integração com a ciência e a tecnologia;

VII o fortalecimento da cidadania, autodeterminação dos povos e solidariedade como fundamentos para 0 futuro da humanidade.

Logo, é explícito a vasta e laboriosa tarefa de trabalhar e executar nas aulas de ciências, português, matemática, ou seja, em todas as disciplinas do currículo escolar, levando em conta, que a Educação Ambiental compõe um dos temas transversais. Dessa forma é de extrema urgência e valia que os educadores tenham uma base de conhecimento acerca deste tema.

Em contrapartida, na medida em que se enxerga os desafios, é preciso superá-los e propor soluções efetivas, como por exemplo a utilização de uma didática com produções artísticas, experiências práticas, atividades de campo, projetos, ou seja, qualquer atividade que norteiam os alunos para um autorreconhecimento como agentes ativos (SATO apud MACHADO, 2002, p.35).

Conforme os PCNs (1997, p. 35) do meio ambiente,

[...] aquisição de conhecimento e informação por parte da escola para que se possa desenvolver um trabalho adequado junto dos alunos. Pela própria natureza da questão ambiental, a aquisição de informações sobre o tema é uma necessidade constante para todos. Isso não significa dizer que os professores deverão saber tudo para que possam desenvolver um trabalho junto dos alunos, mas sim que deverão se dispor a aprender sobre o assunto e, mais do que isso, transmitir aos seus alunos a noção de que o processo de construção e de produção do conhecimento é constante.

É necessário que os educadores compreendam que assim como o conhecimento é construído nas demais disciplinas, o conhecimento em EA é uma construção que está em constante manutenção e busca contínua. Logo, não é de forma repentina que se obtém as mudanças esperadas, mas é um processo gradual.

É válido ressaltar que a temática ambiental apresentada nos PCNs (1997) é fundamentada no objetivo de contribuir para a constituição de cidadãos que busquem o entendimento dos problemas ambientais, e se tornem 
aptos para atuarem diante deles, além de desenvolver um compromisso de cuidar do ecossistema, e tomar decisões baseadas no contexto socioambiental, e para isso é essencial que as escolas se comprometam em trabalhar além de conceitos, definições e de formas superficiais os impactos ambientais.

Todavia é necessário instigar a formação de atitudes, valores e ações que ultrapassem a sala de aula, e essa complexidade configura um enorme desafio para as escolas construírem um processo de ensino e aprendizagem que a abranja de forma plena, norteado por todos os intuitos e princípios da EA no seio educacional.

\section{Tema transversal $x$ disciplina específica}

A EA encara uma outra barreira com relação a sua prática na educação formal, o impasse referente a maneira que ela deve ser abordada para que seja eficaz, trabalhada de maneira transversal, como assegura os PCNs e a PNEA, ou ser trabalhada como uma disciplina curricular, no entanto, a EA configura a plenitude de todos os aspectos que a construíram, a saber, sociais, econômicos, ecológicos dentre outros e ainda os que devem ser construídos na sociedade, buscando promover a construção de uma postura crítica, reflexiva, sensível às questões ambientais e alicerçada no respeito ao meio ambiente, se enxergar como parte integrante dele, além de buscar conhecimentos sobre a temática e distribuir os mesmos, e sobretudo manifestar por meio de atitudes o conhecimento adquirido.

A Educação Ambiental enfrenta este grande desafio referente ao debate em torno da discussão da EA ser trabalhada como um tema transversal ou como uma disciplina curricular, mesmo sendo estabelecido na PNEA a transversalidade, há divergências de opiniões no que se refere a valorização e eficácia da EA ser desenvolvida como um tema transversal (BERNARDES, 2010, p. 1).

Em contrapartida, Reigota (1994) defende que a Educação Ambiental não pode ser considerada como uma simples disciplina, mas como uma perspectiva que interage com as demais disciplinas, ou seja, ela se movimenta entre as múltiplas esferas de conhecimento e deve ser trabalhada de maneira contextualizada e interdisciplinar. Segundo FRAGOSO e NASCIMENTO (2018):

Há tantos desafios para EA construir seu espaço e se legitimar como prática educativa condicionada à transversalidade que pode estar presente em todo lugar, ou até mesmo não estar presente em nenhum lugar como na estrutura curricular de ensino imposta pelos PCNs. Para tanto, basta começar, e buscar o melhor caminho na formação do sujeito ecológico, e na construção da Educação Ambiental nas escolas. 
Como destaca Fragoso e Nascimento (2018) há inúmeros obstáculos para a EA construir seu espaço como um tema transversal, no entanto, é preciso buscar alternativas na constituição do indivíduo com um pensamento ecológico, sustentável e que interaja com o meio ambiente de forma equilibrada, sustentável e consciente das problemáticas ambientais em todo globo terrestre.

A Educação Ambiental não se limita somente a trabalhar os conteúdos relacionados à natureza como a preservação, paisagens naturais, animais, lixo entre outros eixos. A EA tem um caráter que vai além, mais amplo tendo em vista o compromisso com uma construção de valores e comportamentos, que possibilitam ao educando vislumbrar a legítima e genuína interação entre o homem e a natureza que segue pautada no respeito. Todavia uma metodologia pautada na interdisciplinaridade não se resume somente a articulação entre as disciplinas como destaca Leff (apud CABREIRA, 2001):

É que a interdisciplinaridade ambiental não é o somatório nem a articulação de disciplinas; mas também não ocorre à margem delas, como seria colocar em jogo o pensamento complexo fora dos paradigmas estabelecidos pelas ciências. A Educação Ambiental requer que se avance na construção de novos objetos interdisciplinares de estudo através do questionamento dos paradigmas dominantes, da formação dos professores e da incorporação do saber ambiental emergente em novos programas curriculares.

A prática da EA solicita uma evolução na estruturação de novos agentes interdisciplinares, tendo como ponto de partida, a formação dos profissionais da educação e da inserção da dimensão ambiental em propostas curriculares mudadas, visando a práxis transformadora e multidisciplinar, tratando o conhecimento como algo que é construído e que está em constante construção, e não como algo fragmentado ou pronto e acabado.

Coimbra (2005, p.117) corrobora declarando que a abordagem interdisciplinar visa exceder a fragmentação do conhecimento, onde é crucial que de antemão haja uma compreensão globalizada do ambiente, para desenvolver uma atitude enraizada no equilíbrio da relação homem-natureza, haja vista o cenário degradante das ações antrópicas dos últimos anos.

Segundo Neto (2019),

um dos desafios lançados a EA no âmbito escolar, destacamos o de buscar por alternativas teóricas-metodológicas e propostas pedagógicas que garantam o desenvolvimento de uma EA com a perspectiva interdisciplinar, crítica, problematizadora, contextualizada, com ênfase na 
transversalidade, nos processos educacionais que visam a participação do coletivo, considerando a articulação entre as dimensões local e global, na produção e na disseminação de materiais didático pedagógicos, promovendo o caráter contínuo e permanente de formação pela EA, colaborando para uma avaliação crítica-reflexiva.

Reiterando que um dos desafios da EA no âmbito escolar, é buscar por caminhos teórico-metodológicos e escolhas didáticas que promovam uma prática que envolva todo o caráter da EA, ou seja, metodologias que desencadeiam uma postura interdisciplinar, crítica, reflexiva, participativa e significativa, e sobretudo como um tema transversal.

Com isso, revela-se a carência na vertente das práticas pedagógicas atuais, todavia a procura por ultrapassar essas limitações devem instigar a criatividade e determinação que os educadores brasileiros, desde muito tempo já são aptos em superar, tendo em vista que mediar conhecimento sem recursos e materiais adequados é uma tarefa árdua, que na maioria das vezes é pouco valorizada pela sociedade. Contudo suas ações devem promover práticas educativas que devem fomentar um senso socioambiental crítico e atuante (NASCIMENTO et al, 2021, p. 213). Conforme Minéu et al (2016),

a Educação Ambiental (EA) deve ser trabalhada como tema transversal para a transformação da consciência da população quanto à problemática da questão ambiental. Sendo assim, é importante a integração das diversas áreas do conhecimento dentro de um contexto histórico e social. Nesse sentido, entende-se o currículo como a ligação entre a cultura, a sociedade e a educação. Vê-se assim, diante de tantas transformações da natureza, a necessidade de que haja uma melhor compreensão da interação entre homem e meio ambiente. Entretanto, isso não ocorre de forma rápida, sendo necessária a tomada de consciência da população, na qual, sem dúvida, a escola tem um papel fundamental.

A EA deve ser praticada no ambiente escolar como tema transversal, assim como enfatiza Reigota (2004), onde a transversalidade é vista como um pilar fundamental para a aquisição de uma transformação atitudinal, com relação aos problemas ambientais que assolam a presente geração, mas principalmente deve-se analisar e refletir sobre os preocupantes resultados que impactos ambientais deixaram para as gerações futuras.

Com isso, há uma gritante urgência em alcançar melhorias e alternativas metodológicas, para a execução da práxis pedagógica da Educação Ambiental, e para que o processo de ensino e aprendizagem de fato ocorra de forma efetiva, mesmo com sua grande complexidade (COSTA et al, 
2021, p. 245), valorizada e posta em prática pelos professores durantes as ministrações de suas respectivas disciplinas, seja ela, sociologia, geografia, artes ou ciências. Toda sociedade deve cumprir sua parte para minimizar os danos na natureza, e as escolas dispõem de ferramentas significativas e expressivas para a construção de cidadãos sensíveis e conscientes das problemáticas ambientais.

Segundo Purificação e Ferreira (2015, p.62),

a comunidade escolar é um espaço de importante significação para os estudantes. Assim, muitas vezes a escola é uma referência para seus estudantes. É no âmbito escolar que os sujeitos aprendem práticas importantes para sua vida. Destacase nesse estudo a importância das práticas educativas para a Educação Ambiental na comunidade escolar. Nessa busca por entendimento acerca dos cuidados e proteção ao meio ambiente, destaca-se a importância do professor enquanto promulgador dos princípios e práticas em Educação Ambiental nas escolas. É através de suas práticas pedagógicas que o professor ensina quais procedimento coerentes os estudantes devem ter para melhorar o planeta terra e sua qualidade de vida.

Logo as escolas constituem um espaço de referência para o corpo estudantil, e os docentes configuram-se como difusores dos valores e princípios da Educação Ambiental no seio educacional.

Conforme as DCNs (2010, p. 2),

[...] em sua práxis pedagógica, a Educação Ambiental envolve o entendimento de uma educação cidadã, responsável, crítica, participativa, onde cada sujeito aprende com conhecimentos científicos e com o reconhecimento dos saberes tradicionais, possibilitando a tomada de decisões transformadoras a partir do meio ambiente natural ou construído no qual as pessoas se inserem. A Educação Ambiental avança na construção de uma cidadania responsável, estimulando interações mais justas entre os seres humanos e os demais seres que habitam o Planeta, para a construção de um presente e um futuro sustentável, sadio e socialmente justo.

As Diretrizes Curriculares Nacionais (DCNs) estabelecem que a prática da Educação Ambiental requer um envolvimento, ou seja, uma interação com uma educação que seja emancipatória e participativa, com o intuito de desencadear uma relação que emane no respeito com o ecossistema global (DCNs, 2010, p.2). 
Logo é evidente que as DCNs abordam a Educação Ambiental como um mecanismo de mediação, para a construção de uma sociedade que atue com responsabilidade, permitindo a concretização dos conhecimentos e habilidades construídos pelo desenvolvimento da EA, e incentivando a produção de relações sadias entre os seres humanos e o meio ambiente. Para tanto, é indispensável que o ambiente escolar possibilite as condições adequadas para a materialização das finalidades da Educação Ambiental descrita nas DCNs.

Segundo a BNCC (2017, p. 9),

Argumentar com base em fatos, dados e informações confiáveis, para formular, negociar e defender ideias, pontos de vista e decisões comuns que respeitem e promovam os direitos humanos, a consciência socioambiental e o consumo responsável em âmbito local, regional e global, com posicionamento ético em relação ao cuidado de si mesmo, dos outros e do planeta.

A Base Nacional Comum Curricular (BNCC) aponta alguns aspectos da EA de forma bastante sucinta e escassa (OLIVEIRA; NEIMAN, 2020), tendo em vista que ela não define na sua escrita de uma maneira direta e objetiva, a necessidade de trabalhar em sala de aula a EA, e não faz uso da terminologia Educação Ambiental no seu texto.

Isso pode gerar lacunas para eventuais descasos no desenvolvimento da prática deste tema transversal, e de grande relevância dado o contexto ambiental da atualidade. No entanto, neste documento oficial que assegura a base dos currículos escolares nacionais, aponta a necessidade de saberes produzidos em conhecimentos respaldados em informações científicas, promovendo um posicionamento crítico e democrático dos indivíduos, visando a implantação de uma consciência socioambiental.

Além disto, neste documento se destaca a relevância da cooperação que deve ser exercitada em todas as vertentes que integram as interações dos seres humanos com o meio, seja em relação a efêmera e bela borboleta do jardim, até o colega que ele compartilha na sala de aula.

É válido destacar, que as DCNs e a BNCC com respaldo na escrita desses documentos oficiais, não há restrições da prática da EA na Educação Básica, contudo a BNCC dado a sua importância e o reflexo no cotidiano escolar que ela promove, há uma ausência de destaque e ênfase da Educação Ambiental propriamente dita em seu texto, tanto na questão de citação quanto na questão conceitual. Logo, mesmo sem ocorrer restrições explícitas são necessárias melhorias nestes documentos no que se refere a clareza e premência sobre o desenvolvimento da EA no âmbito escolar. 


\section{Conclusões}

Mediante as discussões elencadas, é nítido a importância da Educação Ambiental no ambiente escolar, haja vista a extrema necessidade de promover uma mentalidade sustentável, sensível, equilibrada e consciente dos impactos ambientais, além disso, é essencial a compreensão de que os problemas ambientais afetam toda a sociedade, e não apenas as outras espécies do planeta. Todavia no processo de desenvolvimento da EA nas escolas, há inúmeros obstáculos e limitações para atingir a sua finalidade, que por sua vez, tem por objetivo promover uma transformação atitudinal nos indivíduos, e desenvolver um senso crítico e participativo em relação à dimensão ambiental.

Os desafios enfrentados na prática da Educação Ambiental, se dá principalmente pela complexidade de abordar todo o leque dos aspectos que a formam, sendo eles: socias, políticos, ecológicos, históricos, econômicos, filosóficos entre outros. Em contrapartida, é necessário buscar por alternativas para trabalhar essa temática de maneira eficaz, de modo que promova a criação de uma postura ativa, crítica, reflexiva, interativa e que se concretize em mudanças comportamentais.

Para tanto, é necessário compreender que a práxis pedagógica da Educação Ambiental, não se resume tão somente a realizar colocações durante as aulas sobre conceitos ou sobre a importância de reduzir, reciclar e reutilizar, desenvolver uma prática eficaz da EA, está muito além de apenas tratar desses pontos, é preciso proporcionar e possibilitar situações e condições que construam conhecimentos em todas as vertentes da Educação Ambiental, superando a fragmentação do conhecimento, que na maioria das vezes é posto de maneira isolada e sem contexto, o que desencadeia uma barreira para que ocorra uma educação significativa.

É válido destacar que mesmo com os debates existentes em torno da Educação Ambiental compor os temas transversais, é nítido que a mesma deve ser praticada de maneira transversal, ou seja, com uma didática interdisciplinar, como estabelece a PNEA, os PCNs, as DCNs e a BNCC, haja a vista que a Educação Ambiental e construída a partir de vários aspectos, como citados anteriormente, por isso, ela deve ser colocada em prática de modo que abrange a sua totalidade e grandiosidade.

É de suma relevância pontuar que os documentos oficiais supracitados desencadeiam um grande impacto e influência na construção dos Projetos Políticos Pedagógicos (PPP) e consequentemente, na estrutura curricular das escolas brasileiras, logo é indispensável que nestes documentos a EA tenha lugar de destaque em virtude da sua importância na construção de uma sociedade ecologicamente responsável, pois tais documentos são como uma bússola que norteia, parametriza e direciona a discussão, reflexão e ação na prática da Educação Ambiental nas Instituições de ensino.

Haja vista que a Educação Ambiental configura uma dimensão fundamental no cenário atual, e que deve ser construída levando em 
consideração os pressupostos da sua importância, magnitude e necessidade de materializar essa temática de maneira efetiva no meio escolar. Sendo que, as Instituições de ensino constituem uma ferramenta fundamental e indispensável quanto a concretização dos princípios da Educação Ambiental, tendo em vista que as escolas são ambientes de construção não apenas de conhecimentos, mas de cidadãos. Com isso é evidente o papel da propagação que a Educação exerce na sociedade.

Diante do exposto, mesmo com múltiplos desafios para a efetivação da EA no seio escolar, é preciso superá-los e buscar caminhos e alternativas que promovam uma prática pedagógica, que abrange o contexto local e mundial, com isso, é indispensável que as instituições de ensino, promulguem a relevância de cuidar dos recursos naturais. Como supracitado, as escolas possuem um papel considerável e decisivo na construção de uma sociedade que compreenda os problemas ambientais, ademais é imprescindível que tais conhecimentos estejam atrelados a ações efetivas e que promovam a minimização dos impactos ambientais.

Agradecimentos: À Universidade Federal do Maranhão (UFMA).

\section{Referências}

BRASIL. Lei Federal $\mathbf{n}^{\circ}$ 9.795, de 27 de abril de 1999. Brasília, DF,1999. Disponível em: <http://www.planalto..gov.br/ccivil 03/leis/L9795.htm> Acesso em: 16 jan. 2021.

BRASIL. Decreto $n^{\circ}$ 4.281, de 25 de junho de 2002. Brasília, DF, 2002. Disponível em: <http://www.planalto.gov.br/ccivil 03/decreto/2002/d4281.htm>. Acesso em 16 jan. 2021.

BRASIL. Ministério da Educação e Cultura. Secretaria da Educação Básica. Base Nacional Comum Curricular. Brasília, DF, 2017. Disponível em: $<$ http://www.basenacionalcomum.mec.gov.br/wpcontent/uploads/2018/02/bncc-20dez-site.pdf>. Acesso em: 18 fev. 2021.

BRASIL. Ministério da Educação. Diretrizes Curriculares Nacionais da Educação Básica. MEC, 2013. Brasília, DF, 2013. Disponível em: $<$ http://www.portal.mec.gov.br/docman/julho-2013-pdf/13677-diretrizeseducacao-basica-2013-pdf/file/>. Acesso em: 19 fev. 2021.

BRASIL. Constituição (1988). Constituição da República Federativa do Brasil: texto promulgado em 05 de outubro de 1988. Brasília: Senado Federal, 2013. Disponível em: $<$ http://www.planalto.gov.br/ccivil 03/constituicao/constituicao.htm>. Acesso em: 18 fev. 2021. 
BRASIL. Lei de Diretrizes e Bases. Lei n 9.394, de 20 de dezembro de 1996. Brasília: Presidência da República, 1996. Disponível em: $<$ http://www.portal.mec.gov.br/seed/arquivos/pdf/tvescola/leis/lein9394.pdf> Acesso em: 16 Jan. 2021.

BRASIL. Ministério da Educação. Secretaria da Educação Fundamental. Parâmetros Curriculares Nacionais $5^{\underline{a}}$ a $8^{\underline{a}}$ série. Brasília: MEC/SEF, 1998. Disponível em: $<$ http://www.portal.mec.gov.br/seb/arquivos/pdf/meioambiente.pdf $>$. Acesso em: 19 fev. 2021.

BARBOSA, G.; OLIVEIRA, C. T. Educação Ambiental na Base Nacional Comum Curricular. In: REMEA - Revista Eletrônica Do Mestrado Em Educação Ambiental, Rio Grande, v. 37, n. 1, p. 323-335, jan/abr 2020. Disponível em: <https://www.periodicos.furg.br/remea/article/view/11000/7312>. Acesso em: 09 abr. 2021.

BERNARDES, M. B. J.; PRIETO, E. C. EDUCAÇÃO AMBIENTAL: DISCIPLINA VERSUS TEMA TRANSVERSAL. REMEA - Revista Eletrônica Do Mestrado Em Educação Ambiental, Rio Grande, v. 24, p. 174-185, jan/jul 2010.

BOSA, C. R.; TESSER, H. C. B. Desafios da Educação Ambiental nas escolas municipais do município de Caçador - SC. REMOA, Santa Maria, n. 2, v. 14, p. 2996-3010, mar/2014.

CABREIRA, A. P. M. A inclusão da Educação Ambiental como disciplina curricular nas escolas municipais de São Gabriel - RS: reflexões sobre a educação formal, não formal e informal. Monografia (Especialização em Educação Ambiental) Centro de ciências rurais, Universidade de Santa Maria, p. 29, 2013. Disponível em: $<$ https://www.repositorio.ufsm.br/bitstream/handle/1/799/Cabreira Ana Paula Martins.pdf?sequence=1\&isAllowed=y >. Acesso em: 03 abr. 2021.

COIMBRA, A. S. Interdisciplinaridade e Educação Ambiental: integrando seus princípios necessários. REMEA - Revista Eletrônica Do Mestrado Em Educação Ambiental, Rio Grande, v. 14, p. 115-121, jan/jun 2005.

COSTA, J. A.; BONIFÁCIO, K. M.; MELO, S. P. de A.; LUCENA, R. F. P. A transversalidade da temática ambiental na educação profissional: uma análise dos cursos técnicos integrados do IFS. Revista Brasileira De Educação Ambiental, São Paulo, v. 16, n. 2, p. 232-247, mar/2021. Disponível em: https://www.periodicos.unifesp.br/index.php/revbea/article/view/10736. Acesso em: 09 abr. 2021.

DIMAS, M. S.; NOVAES, A. M. P.; AVELAR, K. E. S. O ensino da Educação Ambiental: desafios e perspectivas. Revista Brasileira De Educação Ambiental, São Paulo, v. 16, n. 2, p. 501-512. Mar/2021. 
FRAGOSO, E; NASCIMENTO, E. C. M. A Educação Ambiental no ensino e na prática escolar da Escola Estadual Cândido Mariano Aquidauana/MS. Ambiente \& Educação: Revista de Educação Ambiental, Rio Grande, n. 1, v. 23, p. 161-184, 2018.

LEFF, E. Educação Ambiental e desenvolvimento sustentável. In: REIGOTA, M. (org.). Verde cotidiano: o meio ambiente em discussão / Rio de Janeiro: DP\&A, 2001. $2^{\mathrm{a}}$ edição.

MACHADO, A.C; TERÁN, A. F. Educação Ambiental: Desafios e Possibilidades no ensino Fundamental I nas escolas públicas. Revistaea, Manaus, XVII, n. 66, jun/dez 2018.2 Disponível em: $<$ https://www.revistaea.org/artigo.php?idartigo=3522>. Acesso em: 03 mar. 2021.

MOURA, J. D. P; HIRATA, C. A. A Educação Ambiental em debate. Revista Eletrônica Pro-Docência/UEL, Londrina, v. 1, n. 5, p. 8, jul/dez 2013.

MINÉU, H. F. S.; TEIXEIRA, R. A.; COLESANTI, M. M. A Educação Ambiental no currículo escolar do ensino médio da rede estadual de Minas Gerais. In: Ambiente \& Educação: Revista de Educação Ambiental, Rio Grande, v. 19, n. 2, p. 18-32, jul/2016.

NASCIMENTO, L. M. B.; NEPOMUCENO, A. L. O.; MANDLATE, C. D.; TAVARES, D. A. B. A emergência do educador ambiental crítico a partir da formação docente: importância do saber socioambiental na construção de projetos de intervenção coletivos. Revista Brasileira de Educação Ambiental, São Paulo, v. 16, n. 2, p. 212-231, mar/2021.

NARCIZO, K. R. S. Uma análise sobre a importância de trabalhar Educação Ambiental nas escolas. Remea - Revista Eletrônica do Mestrado em Educação Ambiental, Rio Grande, v. 22, p. 86-94, jan/jul 2009.

NETO, J. S. Contribuições de Marcos Reigota e de Paulo Freire à práxis pedagógica na perspectiva da Educação Ambiental crítica. Revistaea, Ceará, n. 69 , set/2019.

OLIVEIRA, T. S. A importância da Educação Ambiental e sua política nacional. Âmbito Jurídico, Rio Grande, XIII, n. 75, abr/2010. Disponível em: $<$ https://ambitojuridico.com.br/cadernos/direito-ambiental/a-importancia-daeducacao-ambiental-e-sua-politica-nacional/>. Acesso em: 12 mar. 2021.

OLIVEIRA, E. M. O Que fazer Interdisciplinar. In: A Educação Ambiental uma possível abordagem. Brasília, Edições IBAMA, 2000.

OLIVEIRA, L.; NEIMAN, Z. Educação Ambiental no Âmbito Escolar: Análise do Processo de Elaboração e Aprovação da Base Nacional Comum Curricular (BNCC). Revista Brasileira de Educação Ambiental, v. 15, n. 3, p. 36-52, 2020. 
PURIFICAÇÃO, M. E. S.; FERREIRA, M. O. Educação Ambiental como Tema Transversal: um olhar sobre a prática docente de professores da Reserva de Desenvolvimento Sustentável Estadual Ponta do Tubarão Revista comunicação e Educação Ambiental. Macau, n.1, v.5, p. 52-77, jan/jun, 2015.

SATO, M. Educação Ambiental. São Carlos: Rima, 2002.

SILVA, J. A.; GRZEBIELUKA, D. Educação Ambiental na escola: do Projeto Político Pedagógico a prática docente.REMOA, Santa Maria, n. 3, v. 14, p. 76-101, set/dez 2015.

SOUSA, P. C. O. Educação Ambiental nas escolas: Uma revisão da literatura. TCC, Faculdade Araguaia, Ciências Biológicas. Goiânia, p. 12, 2018. Disponível em: $<$ https://www.researchgate.net/publication/330601366 EDUCACAO AMBIENT AL NAS ESCOLAS UMA REVISAO DA LITERATURA >. Acesso em: 04 abr. 2021. 